Acta Hispanica (2020) Supplementum II: 311-320

\title{
AMÉRICA LATINA: CONFLITO E INTEGRAÇÃO REGIONAL
}

\section{SHIGUENOLI MiYAMOTO}

\author{
Universidade Estadual de Campinas
}

\begin{abstract}
Resumen: A integração sul-americana e latino-americana e a tentativa de formação de blocos tem flutuado ao longo dos anos. Quando se trata de unificar os países do subcontinente, não se tem encontrado nenhum eixo que satisfaça integralmente aos interesses das nações da região. Os processos de cooperação e integração tem avançado mais lentamente do que o desejado. Este texto discute, sob uma perspectiva histórica, as dificuldades e possibilidades de avanço de tais iniciativas em um mundo globalizado e competitivo. Destacamos o papel do Brasil nesses processos.

Palabras clave: integração regional, integração sul-americana, América Latina, política exterior brasileira.
\end{abstract}

Abstract: South American and Latin American integration and attempted block formation have fluctuated over the years. While trying to unify the countries of the subcontinent, no axis has been found that algutine and meets the interests of the nations of the region. The processes of cooperation and integration have been moving more slowly than intended. This text discusses, from a historical perspective, the difficulties and possibilities of advancing such initiatives in a globalized and competitive world. We attach importance to Brazil's role in those processes.

Keywords: Regional Integration, South American Integration, Latin-America, Brazilian Foreign Policy.

\section{Introdução}

Impossibilitados de ascenderem individualmente no cenário cada vez mais competitivo do sistema internacional, a cooperação e, no limite, a integração têm sido instrumentos utilizados pelos países para melhorar o papel desempenhado por eles em termos particulares e em bloco.

Os países têm consciência de que o intercâmbio entre eles e as instituições regionais e internacionais é permeado por relações de poder, de influência e de interesses. Há uma clara percepção da hierarquia existente, ainda que essa não seja formal nem escrita. No quotidiano das negociações envolvendo aspectos políticos, econômicos e estratégicomilitares, o que de fato prevalece é a capacidade que cada agente apresenta individualmente.

Por isso, apesar da soberania que cada pais usufrui, a desigualdade é um elemento real, visível e por todos conhecida. A estrutura do sistema internacional é percebida como fato difícil de ser rompido, possibilitando a ascensão de todos que desejam ocupar lugar de relevo maior nas relações internacionais. Nem ocorre a divisão do poder mundial por livre e espontânea vontade das grandes potências. 
A rigidez do sistema internacional possibilita, por injunções diversas, a ascensão de um ou vários países no tabuleiro mundial de poder. Mérito, arranjos políticos e conveniências poderiam ser listados como fatores que costumam ser ponderados para que um Estado consiga projetar-se no mundo. A estabilidade política e econômica, a menor dependência, sobretudo tecnológica, o aumento de seu poder nacional (em todas as vertentes), são fatores importantes para os países que pretendem ampliar seu raio de ação em termos regionais e, na medida do possível, no sistema internacional.

Além da melhoria dos indicadores, pelo menos outra condição precisa ser atendida. Trata-se do reconhecimento, pela comunidade internacional, de que um Estado tem condições de efetivamente ocupar posto melhor do que o que usufrui atualmente. Isto é, requer anuência, sobretudo das grandes potências, para poder sentar-se ao seu lado em igualdade de condições, ainda que relativas.

A possibilidade de quebra das regras do jogo para entrar à força em determinado círculo de poder é difícil, como o governo brasileiro já teve oportunidade de experimentar. Ainda que deva ser relativizada a retórica do ex-presidente Luiz Inácio Lula da Silva, vale lembrar aqui as declarações por ele feitas quando realçava como uma das prioridades nacionais o ingresso do país no G8, mesmo que tivesse que arrombar a porta. As afirmações de Ângela Merkel enfatizando que as prioridades da União Europeia eram com as dificuldades enfrentadas pelo continente e não a ampliação do círculo, indicaram claramente a diferença entre discurso e intenção versus a fria realidade do poder que cada pais detém.

Outra alternativa para ocupar um lugar junto às grandes potências consistiria na implementação de uma política externa revolucionária, procurando alterar a estrutura do sistema internacional. Alguns fatores devem, contudo, ser considerados. Em primeiro lugar, o país teria que apresentar grande capacidade militar. Em segundo lugar, nem o fato de contemplar recursos dessa natureza significariam o acesso às grandes decisões, como se tem observado. Em terceiro lugar, o uso da força para opor-se às grandes potências faz com que essas individual, ou coletivamente, respondam da mesma forma. Nesse caso, uma desestabilização pode fazer com que o conflito se estenda de forma generalizada. Por isso, países que se aventuram a contestar a ordem vigente, com o uso da força, correm o risco de ser neutralizados, a não ser que já detenham tecnologia nuclear.

Para inserir-se de maneira mais favorável no sistema internacional, a atuação em esferas multilaterais com foco na cooperação e a integração, têm ocupado espaço importante da agenda de países como Brasil e outros semelhantes, designados de emergentes, potências médias, potências regionais, em desenvolvimento, etc. Ao mesmo tempo, por causa de seus próprios interesses, verificam-se conflitos entre os participantes desses processos, conflitos esses que não necessariamente dizem respeito ao uso das armas, mas de discordâncias sobre a interpretação e implementação dos acordos.

Busca-se, portanto, aumentar a capacidade em termos individuais, ou como blocos, procurando ampliar seus espaços e jogar papel de relevo nas relações internacionais. 


\section{As experiências regionais}

As iniciativas visando o aumento da cooperação regional latino-americanas percorrem um longo caminho de 60 anos. De escopo mais amplo, com finalidades políticas, econômicas ou estratégico-militares, abarcando desde o México até a Argentina ou em níveis sub-regionais, pode-se listar um número relativamente grande de instituições procurando aproximar as nações desta parte do mundo. Aglomerando apenas os Estados do Cone Sul, da região andina, da Bacia Amazônica, da América Central, a América do Sul como um todo, com as nações africanas e outras tantas, o que se percebe é que até o momento as intenções jamais conseguiram converter-se em realidade com a magnitude que se esperava.

Ambições grandiosas, capacidades reduzidas, falta de vontade política e dificuldades conjunturais internas e externas, além de divergências interestatais, são fatores que podem ser elencados e que conspiraram para que os processos de cooperação se aprofundassem e a integração efetivamente se tornasse realidade.

Em 18 de fevereiro de 1960, com o Tratado de Montevidéu firmado por sete países (Argentina, Brasil, Chile, Paraguai, Peru, Uruguai e México) e a adesão de mais quatro vizinhos posteriormente (Colômbia e Equador em 1961; Venezuela em 1966 e Bolívia em 1967), as intenções acima dos limites da região podiam ser notadas, ao se falar no estabelecimento de uma zona de livre-comércio entre os latino-americanos. Estipulava-se como limite o ano de 1972, um período de 12 anos após sua criação, para que, segundo o artigo $3^{\circ}$ do capítulo II, os membros da entidade designada Associação Latino-americana de Livre comércio (ALALC) eliminassem "gradualmente, para o essencial de seu comércio recíproco, os gravames e as restrições de toda ordem que incidam sobre a importação de produtos originários de qualquer Parte Contratante". Explicitava-se, ainda no mesmo artigo, que por gravames dever-se-ia entender "os direitos aduaneiros e quaisquer outros encargos de efeitos equivalentes -sejam de caráter fiscal, monetário ou cambial- que incidam sobre as importações" (ALALC-RBPI, 1960).

Uma das dificuldades maiores para implementar acordos desta natureza, e com a amplitude desejada, é o número elevado de parceiros assinantes da proposta. Em regiões como a América Latina nem todos os países usufruem ou passam pelos mesmos estágios de desenvolvimento. Juntar uma dezena de Estados bastante diferenciados torna-se uma tarefa extremamente árdua, porque as demandas e os objetivos de cada governo são muito distintos uns dos outros.

Aqueles que se encontram em estágio mais favorável procuram mercados para colocar seus produtos, ajudando assim sua balança comercial e os interesses dos empresários e indústrias locais. Para os outros menos avançados, propostas em conjunto são percebidas como oportunidades para alavancar seu desenvolvimento, melhorar seus indicadores e reduzir as diferenças que os separam dos demais parceiros. Seguramente, esse fator foi determinante para o sucesso modesto da ALALC nas duas décadas de sua existência. 
A situação internacional com o conflito Leste-Oeste, através, por exemplo da ascensão de Fidel Castro ao poder em Cuba em 1959, a frustrada invasão da Baía dos Porcos em 1961, a crise dos mísseis em 1962, e a intervenção direta norte-americana em assuntos internos das nações latino-americanas pesou igualmente para que a ALALC ficasse em segundo plano nas políticas regionais. A instauração de regimes autoritários nessa mesma década (Brasil em 1964) e nos anos 1970, motivaram a retração dessa primeira tentativa de aglutinar os países da região em uma empreitada comum.

Como consequência desses fatores internos e externos, além de divergências entre as concepções dos empresários da região, aliados à falta de vontades governamentais a ALALC foi substituída pela Associação Latino-americana de Integração (ALADI) em 1980.

A ALADI emerge do novo Tratado de Montevidéu firmado por 11 países. O processo de integração é continuamente mencionado para justificar o novo Tratado, aproveitando a experiência acumulada durante 20 anos, sempre dentro das regras do Acordo Geral de Tarifas e Comércio (GATT).

Agora não se fixava mais datas para se alcançar os objetivos, de integração visando o desenvolvimento regional. Falava-se em longo prazo para se criar, de forma gradual e progressiva, um mercado comum latino-americano. Entre os objetivos arrolados no Art. $2^{\circ}$ do Capítulo I, mencionam-se: "a promoção e regulação do comércio recíproco, a complementação econômica e o desenvolvimento das ações de cooperação econômica que coadjuvem a ampliação de mercados" (ALADI-RPEB, 1980).

A consecução de tais objetivos devia levar em conta que para o Tratado conseguisse avançar dever-se-ia aceitar, segundo o Art. $3^{\circ}$ do mesmo capítulo, o "pluralismo sustentado na vontade dos países membros para sua integração, acima da diversidade que em matéria política e econômica possa existir na região”. Convergência de interesses, flexibilidade, tratamentos diferenciados para cada caso, e ajustes eram outros elementos que precisariam ser contemplados por todos. Pode-se dizer que o processo de integração não se concretizou, mas um número elevado de acordos foi realizado pelos participantes, em termos bilaterais. Países com maior projeção como a Argentina, Brasil e Colômbia, foram os responsáveis pelos acordos no âmbito sul-americano. O distanciamento geográfico pode ser apontado como um dos fatores que dificultaram o prosseguimento e aprofundamento dos mecanismos previstos. Por exemplo, os países da América Central, por sua capacidade menor e não pertencentes ao Tratado, fizeram parte das negociações apenas entre si e com o México, todos situados no Caribe.

O fim dos regimes autoritários na Argentina em 1982 e no Brasil em 1985, levou os rumos da integração para outros caminhos. Adicione-se a isso, as dificuldades enfrentadas pela região em década difícil, por exemplo, com a moratória mexicana em 1982.

Processos simultâneos em termos sub-regionais também se verificavam desde o final dos anos 60, com o próprio Tratado de Cartagena e com o Tratado de Cooperação Amazônica em 1978. Ainda que se pudesse alegar que são instâncias diferenciadas e com objetivos não coincidentes, isso implicava em aceitar a ideia de que ambições mais amplas 
teriam pouca chance de prosperar, pelo menos naqueles anos. A ascensão de Raul Alfonsín ao governo argentino e José Sarney, aproximaram os dois governos após históricos desentendimentos (em grande parte solucionados pós-barragem de Itaipu) assinando-se em 1986 a Ata de Iguaçu, com os protocolos de integração bilateral. Posteriormente, a construção do MERCOSUL se constituiu na iniciativa mais importante no plano regional.

Mais bem sucedida experiência até o momento, a entidade tem passado por inúmeros conflitos que vão desde as denúncias de protecionismos, entendimento de quais setores devem merecer subsídios, até as formas de acordos com outros países ou blocos como a União Europeia, a Associação Europeia de Livre-Comércio ou com a África meridional. O aumento de membros -inicialmente composto por Argentina, Brasil, Paraguai e Uruguai- tem causado, igualmente, divergências no plano político e ideológico, com veto à Venezuela cujo modelo político é contestado por alguns dos parceiros. De qualquer forma, instituições como o MERCOSUL, extensamente analisada nos últimos anos e motivo pelo qual abreviamos aqui nossos comentários sobre a mesma, tem conseguido resistir mais do que as experiências anteriores. Apesar das crises, o comércio dentro do bloco tem sido privilegiado desde seu advento. No dia 6 de setembro de 2019, por exemplo, Brasil e Argentina assinaram acordo automotivo sobre a liberalização do comércio de veículos entre os dois países, ou seja, prevendo livre comércio em 2029.

As transformações que se sucediam, com a Europa e o Japão disputando espaços com os Estados Unidos, a denominada "década perdida", as negociações da Rodada GAT'T Uruguai, a derrocada do modelo soviético, a substituição do GATT pela Organização Mundial do Comércio (OMC) mostram a importância de acontecimentos se realizando em curto espaço de tempo que impactaram todo o sistema internacional incluindo a América Latina.

Ao mesmo tempo, outras instituições como a União das Nações Sul-Americanas e o Conselho de Defesa Sul-Americano passaram a coexistir com as demais iniciativas. Ainda que de escopo diferenciados todas procuram aglutinar os interesses dos Estados sulamericanos.

A criação de tantas entidades ao longo dos anos aponta uma série de problemas. Em primeiro lugar, a consciência de que cada uma delas, no seu tempo, não conseguiu atingir os objetivos almejados, sendo, por isso mesmo, substituídas. A coexistência de vários institutos simultaneamente significa, em segundo lugar, a descrença de que se deve investir maciçamente em apenas uma única política, ainda que essa possa ser ampla, geral e imbuída das melhores intenções e que se concretizada, resolveria parte apreciável dos problemas dos países do subcontinente.

Por isso mesmo, em 26 de maio de 1969, quatro países andinos (Bolívia, Colômbia, Equador e Peru) assinaram o Tratado de Cartagena visando facilitar o intercâmbio subregional. Entre seus objetivos principais, destaca-se a ideia de propiciar a integração econômica e cultural dos países membros. Ao mesmo tempo que alguns deles faziam 
parte geograficamente da Bacia Amazônica, passaram a negociar entre si, excluindo o Brasil, porque o enfoque era andino e não amazônico.

A necessidade de ampliar seus investimentos, exportar produtos semimanufaturados e manufaturados tanto para a África quanto para o próprio continente, fez com que o Brasil para entrar nesse mercado abarcado pelos países andinos propusesse em maio de 1977, o Tratado de Cooperação Amazônica (assinado em 3 de julho de 1978). Desta vez, abrangendo 8 Estados (Bolívia, Brasil, Colômbia, Equador, Guiana, Peru, Suriname e Venezuela), incluindo mesmo a Guiana que não faz parte da Amazônia, mas que se tornou interessante nessa região voltada para o Caribe. Nesse caso, a questão ambiental pesou para que o Brasil tomasse tal iniciativa, porque desde a Conferência de Estocolmo em 1972, passou a sofrer criticas pelos maus cuidados que tinha para com a região.

Juntar esforços seria uma forma de dar uma resposta concertada sobre a soberania da região e a não interferência alheia em negócios que só aos membros da Amazônia deveria caber. Como se observaria depois, o meio ambiente converteu-se em um dos temas mais discutidos internacionalmente, por causa dos impactos globais, independentemente das fronteiras.

Naquela ocasião considerava-se importante garantir "na base da reciprocidade, a mais ampla liberdade de navegação comercial no curso do Amazonas e demais rios amazônicos". Pelo Art. IV deixavam claro o que entendiam pelo uso do meio ambiente na região: "proclamam que o uso e aproveitamento exclusivo dos recursos naturais em seus respectivos territórios é direito inerente à soberania do Estado" (MRE, 1978: 10).

Dificuldades como a falta de investimentos financeiros, a existência de uma secretaria pró-tempore, os anos difíceis da década de 1980 e a falta de vontade política conspiraram para que o TCA pouco fizesse nos próximos lustros; depois foi substituído em 1998 pela Organização do Tratado da Cooperação Amazônica (OTCA), após a criação da Secretaria Permanente em 1995.

Mesmo em anos anteriores, em 23 de abril de 1969, os países do Cone Sul (Argentina, Brasil, Bolívia, Paraguai e Uruguai) assinaram o Tratado da Bacia do Prata visando "conjugar esforços com o objetivo de promover o desenvolvimento harmônico e a integração física da Bacia do Prata e de suas áreas de influência direta e ponderável".

Por iniciativa brasileira, foi aprovada no âmbito da ONU, em 27 de outubro de 1986, a Resolução que criou a Zona de Paz e Cooperação do Atlântico Sul. Com a finalidade de "manter a região livre de medidas de militarização, da corrida armamentista, da presença de bases militares estrangeiras e, sobretudo, de armas nucleares", Argentina, Brasil e Uruguai juntamente com mais 7 países africanos (Cabo Verde, Congo, GuinéBissau, Guiné Equatorial, Libéria, Nigéria e Santo Tomé e Príncipe) comprometem-se a manter-se longe de atitudes belicistas (MRE, 1986: 3-4). No caso brasileiro, em face das divergências entre militares e diplomatas, fez-se questão de diferenciar-se desmilitarização da não-militarização da região (por potências externas à mesma) (MRE, 1986: 77-78). 
$\mathrm{Na}$ América Central e região do Caribe, pode-se também contar inúmeras iniciativas visando aglomerar os países na defesa de políticas e necessidades comuns. Por exemplo, a Comunidade e Mercado Comum do Caribe, criada em 1973 por duas dezenas de países, e substituída pela atual Comunidade do Caribe (CARICOM) em 1997. Diferente das congêneres estritamente compostas por latino-americanas (exceção do TCA com a Guiana e o Suriname), envolve países de língua inglesa e francesa, apresentando como objetivos ampliar a cooperação, promover o livre comércio, e favorecer o movimento do trabalho e do capital (http://www.caricom.org).

Várias iniciativas sub-regionais dificilmente poderiam ser resolvidas dentro de âmbitos como ALALC ou ALADI, por vários motivos: um deles, o fato de que certos assuntos dizem respeito a países de uma determinada parte do continente e que não afetam outros; em segundo lugar, por causa disso, não atendem a necessidade de todos, impedindo que uma política comum pudesse ser estabelecida como regra geral; em terceiro lugar, deve-se considerar a diversidade do continente latino-americano, já que se poderia separá-lo em pelo menos 5 subunidades diferenciadas: Bacia do Prata, Bacia Amazônica, Atlântico Sul, Andes e Caribe. Daí, a necessidade dos acordos e tratados sub-regionais. Por outro lado, poder-se-ia alegar que, dentro de um processo amplo, acordos específicos devessem ser realizados dentro do mesmo, evitando-se criação de instâncias diversas e autônomas para atender as necessidades específicas de cada sub-região.

\section{Os interesses brasileiros e seus agentes}

Praticamente há consenso de que o Brasil tem pautado sua conduta pelo Direito Internacional. Avesso a conflitos e guerras, a política externa brasileira teria investido sempre nas negociações, preferindo essas em vez do conflito. Um dos motivos para explicar esse comportamento é a história de que guerreou com seus vizinhos pela última vez há mais de um século, na Guerra da Tríplice Aliança contra o Paraguai entre 1864 e 1870.

Essa é uma verdade pela metade. O fato de o país não ter conflitos mais acirrados com os vizinhos, não significa que essas possibilidades sejam descartadas. São pelo menos 3 as instâncias que formulam e implementam a política exterior brasileira nas áreas diplomática, militar e econômica.

A última é a que mais tem adquirido peso faz algumas dezenas de anos, mesmo no período militar (1964-1985), no governo de Emilio Garrastazu Médici (1969-1974), quando Antônio Delfim Neto era o ministro da Fazenda. Com as transformações ocorridas na última geração, com o mundo cada vez mais interligado em todos os planos (econômico, cultural, social, etc.), os setores econômicos assumiram papel crescente na definição dos rumos das políticas nacionais.

Nos debates sobre os verdadeiros "donos dos mundo" incluem-se as grandes empresas que determinam o que produzir e consumir. As vertentes diplomática e militar são as mais tradicionais quando se fala em política externa: a primeira, por via do dialogo, 
e a outra pelas armas, e que Aron (1962) exaustivamente discorreu sobre as diferenças entre o soldado e o diplomata.

No exemplo brasileiro, a figura do Barão do Rio Branco é lembrada pela importância que teve na definição do território nacional. As Forças Armadas desempenham papel importante na história nacional no âmbito interno e no plano externo.

Quando se diz que as Forças Armadas nunca foram políticas, esse equívoco deve ser evitado. O que a história tem mostrado é o contrário: é a presença militar nos grandes momentos nacionais. (Carvalho, 2019; Coelho, 1976). Dom Pedro I ao proclamar a independência em 1822 aparece fardado; o advento da República em 1889 teve na liderança um marechal, e os presidentes iniciais foram militares. Nos anos 1930 outros exemplos podem ser resgatados, da mesma forma que a eleição do presidente Eurico Gaspar Dutra em 1946. Com Humberto de Alencar Castelo Branco, mais um marechal e 3 generais, o Brasil enfrentou uma geração de regime militar. Com José Sarney (19851989), o assessor mais próximo e que o acompanhava era o ex-ministro do Exército general Leônidas Pires Gonçalves.

Diplomatas e generais dificilmente dialogam, a não ser quando sejam obrigados. Portadores de opiniões opostas, resultante dos processos de formação profissional, pouco concordam entre si quando se trata de políticas voltadas para integração regional.

Não seria enganoso afirmar que os diplomatas apostam na cooperação visando no limite a integração, da mesma forma que os responsáveis pela área econômica, enquanto o estamento militar interpreta a história conforme a lente conspirativa.

Mas o serviço diplomático não fica infenso quando militares assumem o poder. Prova disso são as denúncias verificadas nos últimos anos sobre a participação de diplomatas nos serviços de segurança e inteligência mapeando cidadãos considerados perigosos para o regime militar e que se encontravam no exterior.

Independente da capacidade que cada agente tem para influenciar os rumos da política exterior, não se pode creditar visão pacifista para o país, em todos os momentos. No período castrense são conhecidas as operações previstas para intervenção no Uruguai se Líber Seregni, líder da Frente Ampla ganhasse as eleições de 1971; recorde-se também apoios explícitos aos golpes da Bolívia ocorrido no mesmo ano e no Chile em 1973 (Grael, 1985; Schilling, 1974).

No decorrer dos anos, dificuldades têm permeado a conduta brasileira nos mecanismos de integração. A guerra da salada de frutas, como ficou conhecido episódio opondo interesses argentinos e brasileiros nos anos 1990 é um bom exemplo para mostrar a dificuldade em compatibilizar interesses. Enquanto os produtores de maçã argentinos procuravam condições melhores de acesso aos consumidores brasileiros, situação difícil porque implicaria na derrocada do similar nacional, as bananas brasileiras também teriam acesso mais difícil para entrar no mercado argentino.

A quantidade de produtos que necessita ser analisada, às dezenas de milhares, têm se convertido em problemas de difícil solução, além de setores da indústria automobilística e mecânica pesada. As reclamações frequentes dos empresários brasileiros e argentinos 
indicam claramente que defendem, mais do que nunca, seus interesses particulares e os lucros que possam advir de entrar em outros mercados, ao mesmo tempo que procuram proteger seus próprios redutos.

Como unidade nacional, o Brasil jamais se opôs, formalmente, a que se aprofundassem processos de cooperação e integração, nos planos sub-regional, sulamericano ou latino-americano. Elementos que corroboram tal afirmação são encontrados nas diversas iniciativas partindo do próprio governo brasileiro. $\mathrm{Na}$ virada do século a América do Sul converteu-se em alvo importante da política externa brasileira. Ao lado da busca de uma vaga como membro permanente no Conselho de Segurança da Organização das Nações Unidas, de cargos diretivos na OMC e Banco Interamericano de Desenvolvimento e em outras entidades, entrada no G-8, a integração ocupou lugar de destaque nas negociações brasileiras. Políticas voltadas para o financiamento de obras de grande porte na América do Sul, através do Banco Nacional de Desenvolvimento Econômico e Social (BNDES), em projetos como a Integração da Infraestrutura Regional Sul-Americana (IIRSA) podem ser listados como alvos da diplomacia nacional. $\mathrm{Na}$ atual gestão do presidente Jair Bolsonaro, eleito em 2019, os ventos parecem ter mudado de direção, negligenciando a integração regional. Dificuldades outras emergem, por exemplo, ao declarar que os argentinos votaram mal ao elegerem Alberto Martinez, ao mesmo tempo que informava que não iria cumprimentar o novo presidente argentino. O chanceler brasileiro Eduardo Azevedo referiu-se ao resultado dizendo que as forças do mal estavam festejando.

\section{Considerações finais}

Falar em integração regional pressupõe considerar os interesses envolvidos, com todos os parceiros. Pelo menos dois elementos necessitam ser ponderados ao se analisar o tema das dificuldades sobre os processos de integração regional. A primeira delas, que foi explorada no texto, diz respeito às próprias dificuldades no relacionamento bilateral e multilateral. Alie-se a esse fator, a ótica defendida sempre de defesa dos interesses nacionais que se sobrepõem às iniciativas multilaterais, porque há necessidade de atender as empresas responsáveis pela produção e exportação de comodities e produtos manufaturados. Em segundo lugar, as dificuldades enfrentadas pelos governos nacionais com seus problemas domésticos. Nesse sentido, os obstáculos que os governantes têm que superar são cruciais para a governabilidade de seus países. Por isso, torna-se necessário resolver as divergências internas que envolvem atores diversos como movimentos sociais, organizações não-governamentais, sindicatos, disputas políticopartidárias, todas almejando influenciar decisões, ocupar cargos e espaços maiores na administração pública. Ligado a este fator doméstico, não se pode menosprezar as dificuldades encontradas pelos governos que não tem conseguido sucesso em suas políticas públicas, e sem atender parcela expressiva da sociedade que, por sua vez, age de forma bastante reivindicativa. Os problemas enfrentados por países como Argentina, 
Brasil, Chile, Bolívia, Peru, Equador e Venezuela, ou seja, quase toda a América do Sul, recentemente, mostram as dificuldades que os governantes tem passado, priorizando a necessidade de resolver seus próprios problemas.

A integração regional não tem conseguido caminhar com a velocidade esperada ao se firmar os inúmeros acordos. Superar essas dificuldades em conjunto, tem se tornado difícil em cenários internos adversos.

Finalmente, valeria a pena refletir sobre algumas dúvidas. Quais os limites de uma possível integração regional e o prazo para que tal objetivo seja alcançado. As experiências indicaram o risco de se estabelecer datas em conjunturas altamente flutuantes. A integração criando-se instâncias superiores implica a necessidade de flexibilizar o conceito de soberania? O que significa integrar mercados e a política externa? Pode-se tomar decisões conjuntas em política externa sem atender os interesses empresariais de cada pais? Como integrar mercados e diplomacia, sem dividir decisões em questões estratégico-militares? Essas dificuldades sempre estiveram presentes nas negociações.

\section{Referências bibliográficas}

ALADI = Asociación Latinoamericana de Intergración (1980). Documento de criação da ALADI. Resenha de Politica Exterior do Brasil, 26(3) jul/set. 133-142.

ALALC = Asociación Latinoamericana de Libre Comercio (1960). Documento de criação da ALALC. Revista Brasileira de Política Internacional, 3(10). 143-159.

Aron, Raymond (1962). Paix et guerre entre les nations. Paris: Calmann-Levy.

Caricom. http://www.caricom.org. Acesso em 11 de março de 2019.

Carvalho, José Murelo de (2019). Forças Armadas e política no Brasil. São Paulo: Todavia Editora.

Coelho, Edmundo Campos (1976). Em busca de identidade. O Exército e a política na sociedade brasileira. Rio de Janeiro: Editora Forense.

Grael, Coronel Dickson M. (1985). Aventura, corrupção e terrorismo. Petrópolis/RJ: Vozes Editora

Ministério das Relações Exteriores (1978). Tratado de Cooperação Amazônica. Brasília: Ministério das Relações Exteriores.

Ministério das Relações Exteriores (1986). Resenha de Politica Exterior do Brasil. Edição Suplementar. Brasília: Ministério das Relações Exteriores, dezembro.

Schilling, Paulo R. (1974). Brasil va a la guerra. Buenos Aires: Schapire Ed. 